\title{
Text World Creation in Advertising Discourse
}

\author{
Laura Hidalgo Downing \\ Universidad Autónoma, Madrid \\ lhidalgo@bosque.sdi.uam.es
}

\begin{abstract}
This article explores the way in which text worlds are created in advertising discourse by analysing linguistic choices and features of context which are crucial in the determination of specific relations between sender(s) and target audience(s), in particular, deixis and frame knowledge. The argument is that a text world model is particularly adequate for the description of the way in which advertising discourse is processed in an active, dynamic, context-dependent way. In this process, addressees reconstruct the world projected in the discourse according to their own cultural and personal knowledge from the linguistic and visual clues provided in the advertisement.
\end{abstract}

\section{Introduction}

The creative potentiality of advertising as a discourse type which plays with the evocation of imaginative situations has been pointed out recently by several authors (see, for example, Carter and Nash, 1990, Cook, 1992, 1994, Semino, 1997). Thus, Semino has observed that "advertising is a genre where the setting up of vivid contexts and discourse situations is often crucial to the achievement of the text producers' goals" (1997: 53). Indeed, some authors have observed the similarities between certain types of advertising and literary writing, in that both discourse types create fictional worlds in order to pursue a communicative purpose; this must be partly due to the fact that many present-day advertisements are less concerned with the listing of "objective properties of things", than in linking "the product to some other entity, effect or person..., creating a fusion which will imbue the characterless product with desirable properties" (Cook, 1992: 105). Thus, the advertisement projects imaginary situations or worlds which invite the addressee to identify 
with the desirable properties displayed in the ad and thus ultimately invites the addressee to buy the product (see, for example, Campos Pardillos, 1995).

This article explores how fictional worlds are created in advertising discourse by analysing linguistic choices and features of context which are crucial in the determination of specific relations between sender(s) and target audience(s), in particular, deixis and frame knowledge. Although advertising discourse establishes complex relations between textual and visual components of ads, this article focuses on the textual aspects and makes only some general references to visual information, since a detailed analysis of the visual aspects would require a different approach. ${ }^{1}$

\subsection{Linguistic choices, contexts and worlds}

Before going further, it is necessary to explain briefly the concepts of linguistic choice, context and world, since they are at the basis of the discussion which follows. The notion of linguistic choice is crucial in functional linguistics (see, for example, Halliday, 1973, 1994): choices made in discourse at the different linguistic levels (lexis, morphology, syntax, phonology) are significant and determine the creation of different meanings. These different meanings are processed contextually and the adequacy of a given message will depend on the relation between the linguistic choices made and the features of context; a standard definition of context includes the following information:

\section{CONTEXT}

- the immediate situational context:

the physical context

the knowledge brought in by the participants in the interaction

the language itself

- the socio-cultural context.

A crucial aspect of context is thus the kind of relationship that is established between the participants in an interaction, a relationship that is determined by features such as age, social status, personal relations, background knowledge, etc. These features are always present in the creation of situations in advertisements, similarly to what happens in other discourse types, and they are exploited for specific purposes.

Duranti and Goodwin (1992) define context on the basis of the distinction between focal event versus background, which is inspired in the distinction between figure and ground in Gestalt psychology. Thus, context is "a frame that surrounds the event being examined" (Duranti and Goodwin, 1992:3). Context is ever-changing and dynamic, so that what may be the focal event at one point in one situation may become part of the background in a different situation. For example, the discussion about the notion of context in my classroom may be at some point a focal event in my life, but it then becomes part of my background when I leave the classroom and become engaged in other activities. A crucial feature of context is the knowledge brought into the situation by the participants, since it determines 
the expectations of participants with regard to the ongoing interaction and, depending on the degree to which knowledge is shared by the participants, it will also determine the development of the interaction itself.

A typical example of two messages with similar propositional form which are manifested linguistically in two different sets of linguistic choices is illustrated in the utterances in (1), which show what is often referred to as register variation ${ }^{2}$ :

(1) a. Give me a hand, mate.

b. Could you please help me with this?

The choice of (1) a. or (1) b. will be determined by the contextual factors mentioned above (relation between participants in situation, socio-cultural context) and their adequacy will also depend on the situation in which they are uttered.

\subsection{World views}

An important implication of the fact that linguistic choice gives rise to different meanings is that linguistic choice also determines different interpretations of reality, or yields different world views. ${ }^{3}$ As explained by Fowler (1986: 17), world views typically reproduce ideologies, in the sense that language, as a tool for the classification and interpretation of reality, constructs "common sense" versions of how things are or should be in the world(s) we inhabit. This indirect relation between human mind and reality, domains which are mediated by language, is stressed by recent cognitive approaches to the study of linguistic phenomena (see de Beaugrande and Dressler, 1981, Lakoff and Johnson, 1980, van Dijk and Kinstch, 1983, Fauconnier, 1985, Semino, 1997, Werth, 1999). Thus, cognitive theories based on the notions of frame, mental models and world emphasise the active role played by the listener or reader of a message in the construction of the world that is evoked by the text in his or her mind. In this sense, talking about discourse understood as text in context means talking not only about the pragmatic factors that determine the choice of linguistic items in interaction, but also about how such choices contribute to the creation of specific worlds or constructions of a given reality.

An analysis of advertising discourse can thus reveal significant details about the way given situations or realities are seen and (re)-constructed by senders and target addressees, and about the individual and more general cultural features which form part of given communities and social groups. This point is summarised by Cook (1992: 182) as follows: "A...reason for interest in advertising is that, as one of the major discourse types which construct our contemporary identity, it enables us to study a part of ourselves." These aspects are the focus of the discussion which follows. 


\section{Advertising as a discourse type}

In this section I review of some of the basic concepts on advertising as a discourse type by paying particular attention to the contributions made by Cook $(1992,1994)$ and by Campos Pardillos (1995), before turning to the description of the text world model proposed for the analysis of advertising discourse. Cook (1992) is a detailed study of advertising as a discourse type from a functional perspective and is complemented by further comments framed within the field of linguistic stylistics in his (1994) work on the discourse of literature. Campos Pardillos (1995) focuses on the function of deictics in the creation of a common ground between sender and receiver in political and advertising discourse. Of the features discussed by Cook and by Campos Pardillos with regard to advertising discourse, the following are particularly significant for the present discussion: first, the description of the context(s) of advertising and the function or functions of advertising discourse, together with a specification of the relations that are established between sender(s) and addressee(s); second, the description of some typical linguistic textual devices which are exploited by advertising discourse to pursue a communicative purpose.

\subsection{Context}

Starting from the general description of advertising discourse, it is necessary to expand on the notion of context mentioned above with specific reference to advertising discourse.

Cook (1992: 1-2) observes that "context" in advertising must be understood to include the following specific features:

\section{FEATURES OF CONTEXT IN ADVERTISING DISCOURSE}

1. Substance (=physical material of ad)

2. Music and pictures

3. Paralanguage (voice, gestures, type and size of letters, etc.)

4. Situation ("the properties and relations of objects and people in the vicinity of the text, as perceived by the participants")

5. Co-text ("text which precedes or follows that under analysis")

6. Intertext ("text which the participants perceive as belonging to other discourse, but which they associate with the text under consideration, and which affects their interpretation")

7. Participants: senders, addressers, addressees and receivers.

8. Function: ("what the text is intended to do by the senders and addressers, or perceived to do by the receivers and addressees")

(Cook, 1992: 1-2)

As in standard works in functional approaches to discourse and text, Cook defines discourse as "text and context together, interacting in a way which is perceived as meaningful and unified by the participants (who are both parts of the context and observers of it)" (Cook, 1992: 2). ${ }^{4}$ I will be particularly interested in discussing advertising discourse 
by focusing on aspects related to the situation, the co-text, the intertext, the participants and the function, that is, those features that foreground the relation between participants in the interaction and textual features.

\subsection{Function}

Although advertising is usually defined by making reference to its predominant function, the conative or persuasive function, which urges people to buy a product, different authors have made reference to the crucial role played by other functions. Thus, Cook (1992: 5) argues that advertising also presents functions such as amusing, informing, pleading, warning, etc., among which emotive and phatic functions play significant roles. Indeed, the emotional and phatic components of advertising discourse form part of a more complex phenomenon which is crucial in advertising and which Cook, following Goffman, calls display (1992: 147-48). Display has as its main purpose "to establish and maintain identity" differentiating that identity from others (Cook, 1992: 147); "Like spells and prayers, display elevates the signifier - the name of a product, a team or a political party - above what it signifies." (Cook, 1992: 148). While in other social contexts or activities such as prayer, incantation or bragging, participants take active part in the discourse, in activities such as advertising participants only engage in the discourse in a more passive way; in this sense, "We express our identity by accepting someone else's product, political programme, sporting prowess or art, rather than by making our own." (Cook, 1992: 148).

The process of identification between addressee and the situation represented in the advertisement can be described as a relation which involves four participant worlds: (1) the world of the sender, where the product is manufactured, (2) the fictional world where characters present the product or are associated with it, (3) the fantasy world of the receiver and (4) the real world of the receiver (Cook, 1992: 177). Cook argues that the aim of senders is "to push the product, via the world of fiction and fantasy, into the real world of the consumer" (1992: 177). For this to be possible, enough contact has to be achieved between the different worlds, between the worlds of fiction and fantasy on the one hand and the real worlds of senders and receivers on the other. In order to pursue this objective, advertising discourse makes use of a series of strategies, among which textual-discursive strategies play a significant role. Indeed, the creative manipulation of language, the exploitation of ambiguity and indeterminacy and the appeal to personal and emotional experiences (affective, evaluative, aesthetic functions) seem to bring advertising discourse close to literary discourse.

According to Cook (1994: 193), one of the crucial differences between literary discourse and advertising discourse is that while literary discourse typically performs the function that Cook defines as the function of cognitive change, that is, the modification or challenging of the reader's world schemata leading to a revaluation of concepts, advertising discourse tends to be conservative in the sense that it reinforces already existing and accepted world schemata, thus reinforcing the feeling of identity of a given social group. I am not sure that this claim is totally valid in our contemporary western society, in which 
advertising has developed such an important role in the orientation of people's wishes and desires. Let us take, for example, those ads which make a point of shocking a certain type of audience while appealing to another, such as ads directed at young people where the young characters in some way challenge established behaviour as understood by more mature generations. It is true that the shocking and challenging dimension of these ads exploits cultural values which are already present in a given social group and are presented as desirable in the advertisement, but it could be argued that these advertisements also pursue in some way the objective of "cognitively changing " potential addressees by inviting them to form part of a new social identity by buying the product. In many cases, it is true that this invitation to change cognitive schemata in favour of new ones is ambiguous in the sense that a compromise is proposed between a conservative schema and an innovative schema. This is the case, for example, of a car advertisement where a young man attends mass and is shown as having a pierced tongue where he is receiving the sacrament of communion. In this ad, the conservative schema of religious belief is presented as compatible with the more challenging schema of body piercing, so that the owner of the car will potentially be appealing both to people with religious feelings and to those who favour body piercing, or, more significantly, to persons who hold these apparently incompatible wishes simultaneously. Ultimately, of course, the aim of the sender (or ad producer) is to reach as many future consumers as possible, so that the functions of display and establishing identity are a means to an end, that of persuasion.

What is clear is that both literary discourse and advertising discourse often defeat expectations regarding the textual and linguistic features, thus challenging what Cook defines as textual and language schemata (schemata which govern textual genres and linguistic properties of texts), to which I turn now.

\subsection{Textual-discursive strategies}

Like other discourse types which make a creative use of language, such as fictional writing, poetry, joke telling and humour, advertising discourse "indulges in code play" (Cook, 1992: 277). This is observed at the different levels of linguistic analysis, ranging from that of graphology and phonology to lexis, syntax and textual rhetoric, thus creating idiosyncratic discursive patterns. Thus, for example, puns are exploited to create multiple meanings, and metaphor and metonymy are used to introduce desirable domains and experiences with which the product is associated. Thus, in an advertisement for a company called Infonet, we can read the following:

(2) In global communications one supplier is better than many

The message plays with the ambiguity of the structure as meaning both that having only one supplier is better than having several suppliers, and that having one specific supplier (Infonet, it is assumed) is better than having others. Cook gives an example of metonymic 
association in an ad of the car Ford Fiesta, which is shown in a fictional situation where the characters go to a fiesta. Consequently, addressees are not just being sold the product, they are sold themselves "in an attractive person, role or environment" (Cook, 1992: 108). As is illustrated in the discussion on the nature of text worlds in advertisements in sections 3 and 4 below, the role of frame knowledge evocation plays a crucial role. Indeed, frame evocation is part of a more general discursive strategy where the creation of implied meanings is primary over the denotational descriptive function of language.

\subsubsection{The conversational tone of advertising discourse}

Implied meanings may be created by a great variety of means, some of which have already been mentioned, but there are three aspects which need to be discussed, namely the use of pronouns, ellipsis and presupposition. These linguistic features contribute to the creation of a conversational tone which is typical of much advertising discourse (See Cook, 1992: 171, Campos Pardillos, 1995: 66). This dialogic tone is often present even when the text in the advertisement is apparently a monologue, and it has the effect of directly involving the addressee in the discourse situation, appealing directly to his or her knowledge, interests and emotions (see Campos Pardillos, 1995: 59-60).

Personal pronouns play a crucial role because of their nature as deictic elements, that is, as linguistic items which have a variable component of meaning which is assigned contextually.

In face-to-face interaction most of the deictic information relevant to the discourse situation, such as the time, the place and the participants, is directly observable from the immediate physical context, so it does not have to be mentioned. However, in written communication, in which there is typically a mismatch between the time of coding the message and the time of receiving the message the relevant deictic information necessary to understand the text is typically mentioned explicitly. This is obvious, for example, in fictional writing, where the text makes explicit the time and the location of the events narrated. Advertisements seem to be mixed modes, with often more features of face-to-face interaction; this effect is created partly by means of visual support, which provides ostensive clues regarding deictic information, and partly by direct address to the reader, which has the effect of directly involving the addressee in the situation evoked by the advertisement. As argued by Campos Pardillos $(1995,60)$, "the role of all deictics is to contextualize and place the text within a certain environment: the addressee's."

Thus, the "you" of advertisements refers both to characters in the fictional situation depicted in the advertisement and to the (multiple) addressees, the " $\mathrm{I}$ " is both the manufacturer and the interlocutor in the fictional situation, often an expert or adviser, and, finally, the "he" or "she" is often the person who did not buy the product (Cook, 1992: 155) or a competing company. A relationship of intimacy, trust and confidence is established by means of the direct address to the receiver by using "you", which may contrast with other more distant third person referents. Consider the text for the following advertisement of the company UPS: 
(3) Don't you

hate it when

who signed

for your package

is a mystery?

Consider it solved

You send out an important shipment. They tell you they haven't got it. They tell you they can't find it. They tell you no one there seems to know anything about it. It's enough to make you crazy. But when you ship with UPS, it's something you never have to deal with.....

The advertisement continues in the same line. What is interesting for the purposes of the present discussion is that this ad illustrates clearly the typical use of pronouns in ads: the receiver is addressed directly by means of "you", thus establishing a dialogue between sender and receiver, and competing companies are referred to as "they", thus establishing a distance between the advertised company and the receiver on the one hand (first and second person interlocutors) and other companies on the other (third person interlocutors).

In languages with a tu/vous distinction, such as Spanish, the choice of the second person pronoun will determine the relationship between sender-narrator in the fictional world of the ad and addressee, either as more informal, less authoritative and close, or more formal, more authoritative and distant (see Brown and Gilman, 1964), as is seen in the discussion of two advertisements from Spanish press in section 4.1.

\subsubsection{Ellipsis, presupposition and shared knowledge in advertising discourse}

Ellipsis and presupposition also contribute to the creation of a conversational tone in advertising discourse by establishing a relationship between characters in the fictional world and addressee which is based on the assumption that that there is a sufficient amount of shared knowledge to determine a feeling of immediacy, trust, informality and intimacy. Thus, as Cook (1992: 176) argues, it is what is not said in discourse that is most important, as it reflects what people take for granted and assume to be the case. In this sense, the role of shared knowledge becomes particularly significant, since many advertisements play with intertextual references - to other text types such as songs, poems, other texts, and to other ads - which build upon the shared experiences of interlocutors.

Carter and Nash provide the following example of an advertisement where both the use of direct address to the receiver together with the use of questions and ellipsis contribute to the creation of a dialogic structure with a strong persuasive component (Carter and Nash, 1990: 46-47):

(4) Have you had the great Sunday car washing ritual? 
Have you got better things to do with a car than run round it with a rag, and show it off to your neighbours?

Then the Maxi is for you.

Because the Maxi was made for doing things....

In this advertisement, the combination of direct address to the reader and of ellipsis directly involve the reader and elicit answers to the questions which lead on to the utterance which follows. The conversational tone is present both in the structure - questions, ellipsis and in the choice of vocabulary.

Campos Pardillos (1995) further argues that deictics play a crucial function in the creation of presupposed and, thus implicitly shared, meanings in advertisements. Thus, the function of deictics such as here or today is not the typical presentational function of expressions such as Here is the book I told you about. Rather, deictics are more often used in advertisements to create a common space between sender and receiver where indexicals refer into and "where the addressee is invited to enter" (Campos Pardillos, 1995: 63). This leads Campos Pardillos to propose a modification of the traditional classification of deictics into two main types, proximal and distal, as follows: "we might conclude that indexical frames are no longer two...; to the spaces corresponding to either participant in discourse we might add a third one" where sender and receiver meet (Campos Pardillos, 1995: 66). As argued by Campos Pardillos (1995, 60), advertisements thus create "a presumed (and obviously false) time-space frame where advertiser and consumer coexist." This is represented as follows:

$\begin{array}{ll}\text { Space 1 } & \text { Space 2 } \\ \text { I } & \text { you } \\ \text { Here } & \text { there } \\ \text { Now } & \text { then } \\ \text { (Campos Pardilios, 1995: 66) }\end{array}$

The idea of space creation in discourse processing is the basis of the cognitive discourse model which is described in the following section.

\section{Text world theory as discourse theory}

Text world theory as developed by authors such as Semino (1997) and Werth (1999) brings together notions derived from the text linguistics tradition (see de Beaugrande and Dressler, 1981, van Dijk and Kinstch, 1983) and other notions from more recent cognitive theories on metaphor and mental spaces (see, for example, Lakoff and Johnson, 1980, Fauconnier, 1985). These theories share the view of text processing as a dynamic event where both author and reader play active roles; in this perspective, negotiation is a crucial element of interaction, as it determines the nature and the outcome of the ongoing discourse. Thus, in 
Werth (1995b: 95), discourse in general terms, including written discourse situations, is "a deliberate and joint effort on the part of producer and receiver to build up a 'world' within which the propositions advanced are coherent and make sense." This definition is based upon a dynamic view of the process of communication and the cognitive assumption that participants in communicative situations actively construct the shared contexts which arise from the interaction between the information in the text and the knowledge brought by the participants to the discourse situation. This view is particularly adequate for an account of how receivers of advertisements construct versions of the fictional worlds represented in the advertisements, and how these worlds are related to the "real" and the "fantasy" worlds of the receivers.

\subsection{Text worlds and the world-building process}

If we consider more closely the notion of text world and the type of information that is organised in a text world system, the following distinction may be established: while "the discourse world is the situational context surrounding the speech event itself" (Werth, 1995a: 49), the text world is defined as follows:

A world (...) is a conceptual domain representing a state of affairs. A text world, in particular, represents the principal state of affairs expressed in the discourse. First, the world must be defined: this is effected by means of the deictic and referential elements nominated in the text, and fleshed out from knowledge (specifically, knowledge frames) (Werth. 1995a: 78).

The cognitive nature of the text world notion is also present in Semino, who argues that "When we read, we actively infer a text world 'behind' the text. By 'text world' I mean the context, scenario or type of reality that is evoked in our minds during reading and that (we conclude) is referred to by the text..." (1997: 1). An important implication deriving from the cognitive conception of text is the fact that text worlds are not fixed entities which are perceived in the same way by different readers; in fact, there is no guarantee that receivers will construct the text world that was intended by the author of the text, as each individual will construct his or her own text world according to different experiences.

As was pointed out in one of the quotations by Werth above, the text world is first defined by the deictic terms and is then filled out by the knowledge frames. Thus, world building is first carried out by means of specifying the relevant deictic information and by indicating the possible deictic shifts (shifts in time, such as flashbacks, or shifts in location). Additionally, world building also involves those propositions which contain world building predicates of different types and the activation of knowledge frames. Thus, world building includes the creation of the following types of conceptual domains:

a. deictic: space and time.

b. cognitive: believe, realise, seem...

c. intentional: want, must, in order to... 
d. representational: on TV, in the picture, in his mind...

e. hypothetical: if.., had you not...

f. epistemic: perhaps, possibly, certainly...

The process of world building is contrasted with the process of function advancing, which is carried out by those propositions which make the discourse move forward. The function advancing component is typically related to the register-type of the text, and, consequently, to its predominant functions. Thus, the function-advancing component of a narrative will have the purpose of making the plot move forward, while that of a description will be making a description (of a character, a scene) move forward. In advertising discourse, the function advancing component is not always so easily identifiable, in the sense that it is not always manifested in propositional form but, rather, in the selection of specific lexical items or in the juxtaposition of text and images.

The relation between the different conceptual domains which are created in the worldbuilding process is hierarchical: thus, the discourse world is the broader cognitive domain, being fed from the immediate situation in which the interaction takes place; the textual world constitutes the next internal layer, being a conceptualisation of the specific event which is in focus during the interaction; finally, other domains internal to the text world may be identified, termed subworlds, which arise as departures from the parameters which have been established in the text world (departures in deictic information, propositional attitude or modalisations).

\subsubsection{Deixis}

We have seen that in the world building process, deictic elements play crucial roles. It can be said that deictic terms introduce the spatio-temporal coordinates of a discourse situation with regard to a deictic centre or point of reference, which is egocentric, or oriented from the point of view of the speaker. Deictic elements are typically defined as "grammaticalisations and lexicalisations of referential information which is processed contextually" (see Green, 1995: 12) and as elements which foreground the relationship between the language system, the subjectivity of the encoder and the context of utterance (Green, ibid.). Deixis is considered to be egocentric or an expression of subjectivity because an opposition is established between the I-here-now, which contextually indicates what is close to the speaker, and distant terms such as he/she/there/then. According to Werth (1995a: 64) deixis is in fact part of the modality function of language, i.e. the situating of the information with respect to the current context." Thus, deixis can be said to have two main components, spatio-temporality (locative information) and egocentricity (directional information) (Werth, 1995a: 65).

A shift in the use of deictic terms, from, for example, proximal to distal or viceversa, might indicate shifts in spatio-temporal domains or in the narrative mode or mode of discourse. Similarly, the choice of specific deictic terms instead of others might also provide clues regarding the type of relation that is established between the voice in the advertising 
text and the target addressee. Finally, the fact that deictic terms can be said to have two meaning components, a basic sense which is fixed, and a pragmatic meaning which is variable and is determined contextually, can be exploited in certain texts in order to create multiple meanings which will be associated with the different contexts evoked by the deictic terms.

The spatio-temporal coordinates, which are expressed by means of deictic terms, define the boundaries of a given world, be it a real or a fictional situation. For example, consider the first two lines of one of the advertisements which I will discuss in depth in section 4:

\section{(5) BE THERE}

He sat in his car and prayed for a flight delay

The text, which is reproduced in its complete version in the following section, is accompanied by a picture of an airport flight departure lounge where several people are sitting waiting and there is an empty seat foregrounded by a pointing arrow. One of the first things that draw the reader's attention is of course the possible referent of the deictic THERE, which is not that obvious. The reader must follow a process of inferencing in order to deduce, by means of visual and textual clues, that the deictic refers to the empty seat in the airport waiting lounge. In linguistic terms, the text is playing with the indexical nature of the deictic term, which makes it possible for the term to refer to different places; the assignment of a referent can only be carried out contextually. At the same time, by singling out a specific place in a specific context the deictic will also be creating or enlarging context, by selecting a given background which is then expanded and enriched by relevant knowledge frames. Other questions that arise when reading this advertisement are who is $h e$ and who is addressed by the direct address form BE THERE, both of which have to do with the contextual interpretation of deictic terms. I return to the advertisement in section 4 below.

\subsubsection{Frame knowledge}

Knowledge frames are elements which contribute to the process of building text worlds by evoking the personal and cultural knowledge which is relevant for the coherence of a given text; as such, frames might provide interesting information regarding the type of world that is being represented in a given situation. A frame is defined in the editor's preface to Werth's (1995b) article as "a cognitive structure of culturally determined assumptions and expectations developed from past experiences with similar situations" (1995b: 192). Werth acknowledges the similarities of his concept of frame with other similar concepts used by cognitive linguists, such as for example Lakoff's (1987) notion of ICM. However, Werth uses Fillmore's (1985) notion of frame as his main source of inspiration. Thus, for Werth, a frame, following Fillmore is "an area of experience in a particular culture" (1999:106). It is also a "cognitive space, mapping out an experiential category", being fuzzy-edged and associated to the notion of prototype. More specifically, Werth describes the process by 
which frames are created as follows: "speakers build up a repertoire of scenes which encapsulate the expectations about how particular situation-types will develop" (1999: 104). This means that a frame does not correspond to an actual situation, but rather, "a frame... is a distillation from a pattern of text worlds, representing complexes of situation-types and background knowledge."

Schank (1982: 90) proposes a type of cognitive structure (the Memory Organisation Packet, or MOP) which contains the following type of information, organised by the MOP:

- a prototype

- a set of expectations organised in terms of the prototype

- a set of memories organised in terms of the previously failed expectations of the prototype - a characteristic goal

It may be argued that these features are present in cognitive knowledge structures in general terms, and that they determine the way individuals process texts. Furthermore, the role of frame knowledge is crucial in the processing of information in the text because it allows for the introduction of the default elements, that is, the information which conforms to already existing patterns and is presented as given. Thus, Werth (1995a:69) argues that "text worlds seem to contain a mixture of pre-fabricated knowledge, originating in existing frames, and new, discourse-specific knowledge. "While frame knowledge is typically coded in the form of definite noun phrases which enter already existing reference chains, the new discourse-based elements are typically coded in the form of indefinite noun phrases and act potentially as first mentions of new reference chains (Werth, 1995a: 69). This distinction between the coding of what is presented as old or new information is crucial in the construction of text worlds in advertising, since what is presented as old information typically codes the presuppositions of a discourse, that is, the information which is taken for granted and accepted to be true, and which, as a consequence, has an ideological basis.

\section{World creation in advertising}

I turn now to the discussion of how the combination of deictic elements and the activation of knowledge frames, in combination with other related linguistic choices, contributes to the projection of worlds which are addressed at specific target audiences.

\subsection{Deixis and frame knowledge activation in advertisements}

Let us start by considering text 1 , which was already introduced in section 3.1.1. above; text 1 illustrates clearly the function of deictic terms and of frame knowledge in the construction of cognitive textual domains: 


\section{Text 1}

\section{BE THERE}

He sat in his car and prayed for a flight delay. It seemed odd. Five miles of motorway roadworks had made him late in the first place. But now it was his only hope. Once again, he edged six inches to the bumper in front. But it was no good. He hadn't gone by train. He was going nowhere.

For services and fare information please call 0345484950

\section{transpenninexpress}

trains right across the north

In text 1 , it may be argued that two different domains are created and that this distinction is reflected in the choice of different deictic terms and of two different sets of knowledge frames which encode two different experiences. The first domain is evoked by the word there already mentioned above, and by the visual clues which represent a flight departure lounge with three people sitting in a relaxed attitude. The second domain is created in the second part of the text, which is of a narrative type. The shift in domain is indicated by a shift in mode of discourse, from direct address in be there to third person narration (he sat in his car). As explained in section 2 above, the direct address to the audience creates an effect of immediacy and direct involvement with the situation described, while the shift to third person narration has a distancing effect. The distancing effect is reinforced by the contrastive use of present and past tenses in the text, which determine the temporal situation of the event with regard to the situation reflected in the picture. The use of the adverb now seems to indicate that the event told in the narrative is simultaneous with the event reflected in the picture and identified by there. An opposition is thus established between the situation represented in the picture and the situation described in the text (he edged six inches to the bumper in front). The situation in the text is seen as a result of previous events, coded in past perfect (motorway roadworks had made him late, he hadn't gone by train). The conclusion is expressed as an opposition to the initial there by indicating that the driver is going nowhere: the referential function of there, situating the addressee in the positively valued domain, is sharply contrasted to the non-referential nature of the negative adverb nowhere, which denies the possibility of being situated in a relevant location for the person who has not taken the train. Similarly, the two preceding clauses, which are also negative (It was no good. He hadn't gone by train), underline the final point by evoking the positive domain (travelling by train) which is denied in the negatively valued domain (travelling by car).

The sets of evoked frames introduced by the two different deictic domains are also radically different: while the picture creates an atmosphere of relax and calm where the positive expectations regarding an aeroplane trip frame are confirmed, in the text these expectations are defeated, and the goal of reaching the airport on time is not achieved. This analysis can be systematised in the following diagram, which represents a possible AEROPLANE FRAME, which is activated in the text and contrasts with a CAR TRIP frame (cf. van Dijk, 1977). 


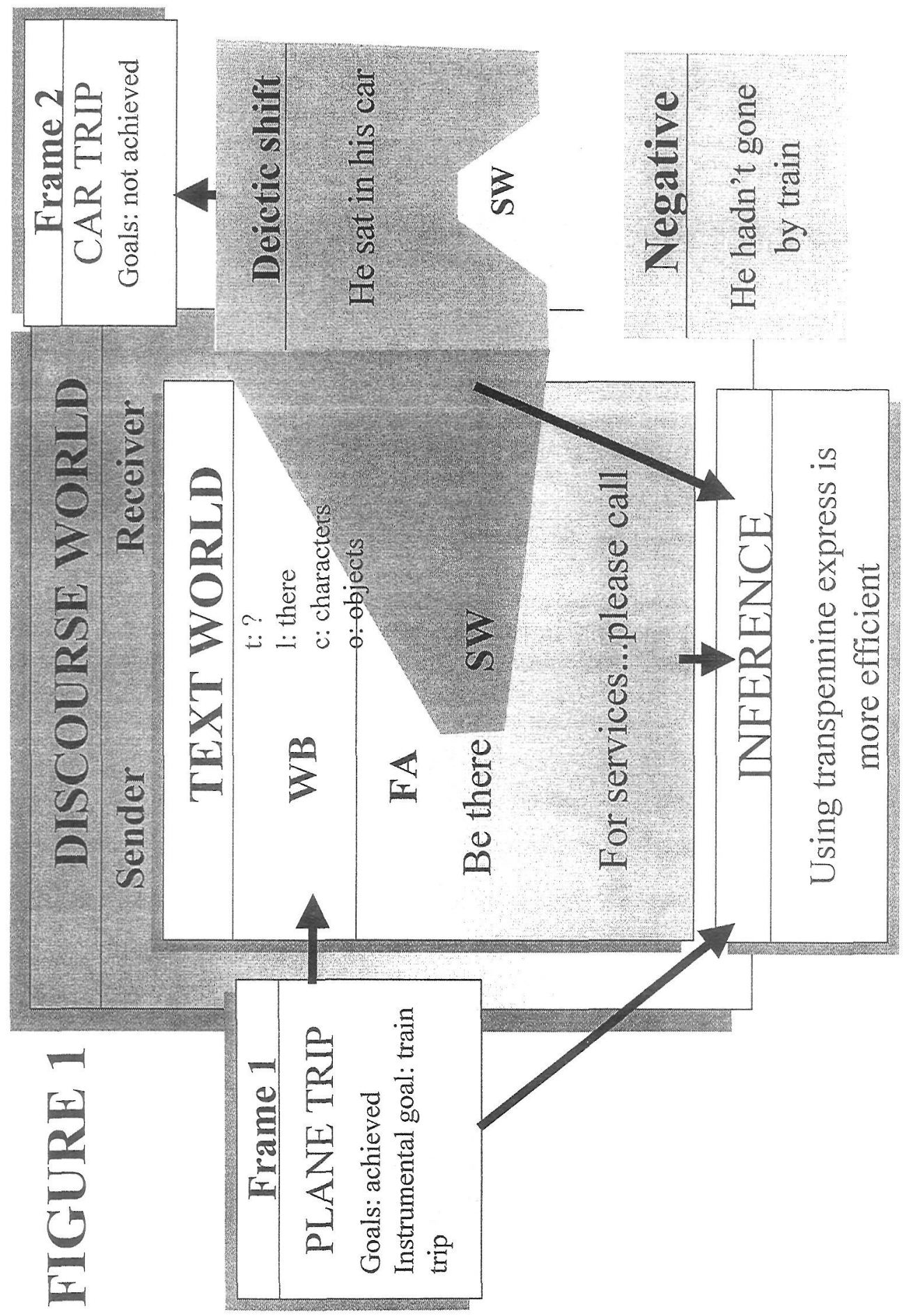




\section{FRAME 1: AEROPLANE TRIP}

goals: buy ticket, get to airport on time, check in, wait in lounge, board plane, etc.

\section{Specific goals and scenes activated in the two domains}

instrumental goal: travelling by train instrumental goal: travelling by car scene: waiting in lounge

scene: sitting in traffic jam

The goal get to airport on time evokes a series of associated instrumental goals where an opposition is established between travelling by car and travelling by train, and the associated resulting scenes: waiting in lounge and sitting in traffic jam. An indirect evaluation is made of the two instrumental goals and the associated scenes, in such a way that travelling by car is negatively evaluated as a result. This leads to the point of the advertisement which is to infer the advantages of travelling by train, more specifically, of using the transpennine express service.

The internal organisation of the discourse and text world spaces corresponding to text 1 can be schematically represented as shown in Figure 1.

In Figure 1. the Discourse World is the conceptual domain which contains the other spaces and where the interaction between sender and receiver takes place. The world building component of the text world is determined by the locative there and by the characters and objects in the visual part of the ad. The function advancing component corresponds to the persuasive utterances be (there) and for services...please call... Subworlds are represented as projected spaces which depart from the parameters of the text world. Thus, the deictic shift into third person narration constitutes a subworld, within which a further negative subworld may be identified. Lexical items in the text world and subworlds evoke at least two knowledge frames, the aeroplane trip and the car trip frames, and, presumably, also a train trip frame, though this is not represented in the figure. Finally, a relevance-based inference may be said to take place in such a way that a reader will conclude that using transpennine express is more efficient than using other means of transport.

Text 2 illustrates the function of hypothetical subworlds (here introduced by if-clauses) in the world-building process:

\section{Text 2}

\section{TONIGHT, FIND YOURSELF IN A MAJOR MOVING PICTURE}

If you long for passion and laughter. If you live for action and drama. If you really love movies the way Sky loves movies, then we have some exciting news: the brand new home of the biggest box office movies will be in your home. It's the Sky premier channel from Sky Movies and we believe it will bring you closer together. 


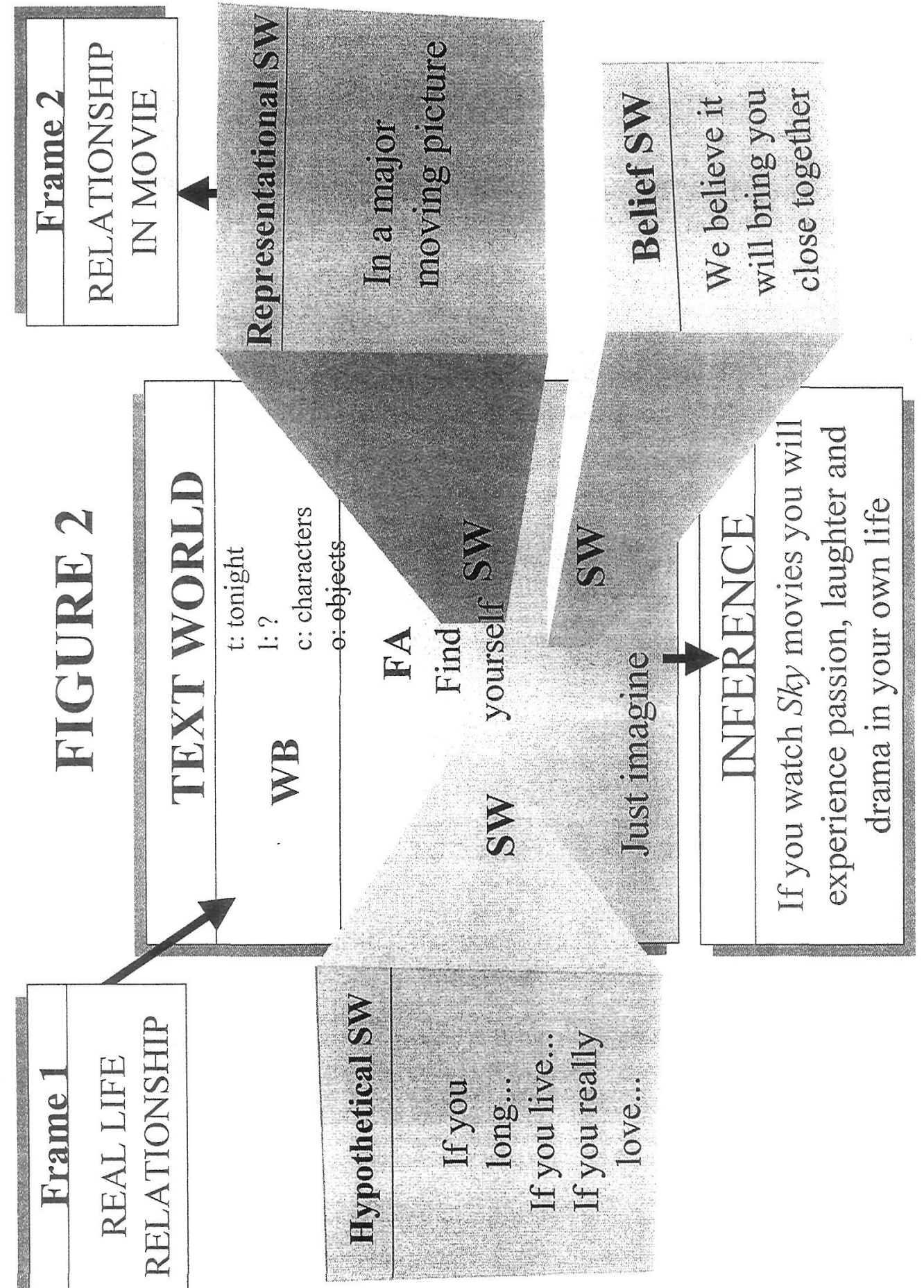


The similarities between the discourse of advertising and face-to-face interaction can be observed in text 2 , in the use of the deictic tonight, which receives its pragmatic meaning by being used in a specific context. A reader will interpret the deictic to refer to the evening of the day specified in the newspaper, usually the same day the paper is read. ${ }^{5}$ As in text 1 , the direct address to the reader by means of the pronouns you and yourself creates a feeling of immediacy and involvement with the discourse situation. This effect is reinforced by the visual support, which is a close-up of two faces, a man and a woman's, indicating a close and happy relationship. The text which follows the first words already presents a subworld of the representational type (in a major moving picture). This is followed by a shift in hypothetical domain, thus introducing a possible situation in which the addressee is situated. The if-clauses introduce hypothetical subworlds which construct potential wishes of addressees; these wishes are more specifically manifested as knowledge frames which give body to the hypothetical situation. This is defined by a set of properties which ambiguously refer both to the features of the movies and to the qualities expected of a real-life relationship: passion, laughter, action, drama. Thus, the frames evoked by these lexical items evoke information regarding both the fictional world represented in the advertisement and the fantasy world of the receivers. The entity to which these properties are assigned, Sky Premier channel, is situated close to the addressee by means of the conclusion of the hypothetical subworlds (will be in your home), reinforced by a further belief-subworld (we believe it will bring you close together) thus implying that the properties described are both in the TV programme and in the home where the programme is watched. The process of identification with the described situation takes place by means of establishing a deterministic relationship between the projection of a hypothetical domain and its perception as real. It is as if perceiving the pretended domain - watching the film - makes its properties real, first by being part of the wish worlds of receivers, and then by becoming part of their real life relationships. These relationships are represented schematically in figure 2 .

Figure 2 shows a text world defined by the time referent tonight and by the characters in the visual component of the ad. The text world contains several subworlds (representational, hypothetical and belief subworlds) together with the evoked frames corresponding to the knowledge about a real life relationship and a relationship in a movie. The figure is not complete in the sense that further internal layers may be identified, such as the modal subworlds which present the conclusion within the hypothetical subworlds, and the modal subworld within the belief subworld. Figure 2 thus represents an extremely complex pattern of embedded projected domains within a single text world. The function-advancing component of the text world is found in the opening and closing sections (find yourself... and just imagine). As in text 1, a relevance-based inference is produced, by which a reader will infer that by watching Sky movies the experiences of the movies will be felt also in the real life relationship.

Further distinctions between the kinds of worlds that are evoked in advertisements and the consequent differences in target audiences may be established by the choice of $t u$ or usted as social deictics in Spanish advertisements; this phenomenon is obviously not observable in English texts. Below are two examples of two different car advertisements, 
each of which makes a different choice in the tu/usted system, with a consequent difference in the target audience to whom the advertisement is addressed.

\section{Text 3}

¿No empieza a cansarte que lo pequeño sea siempre pequeño? ¿No crees que lo ligero debería ser resistente? ¿Y por qué no puede ser lo bello práctico? ¿No piensas que va siendo hora que todo cambie? Desafia la lógica, rompe con todo, ahora tienes el nuevo Yaris de Toyota. Lo pequeño por fuera se hace grande por dentro. Lo ligero resulta resistente, por su estructura interior reforzada. Y la belleza de su diseño esconde la tecnología más práctica y avanzada. Y ahora ¿Qué es lo lógico? Lo más lógico es tener un Yaris.

\section{El nuevo YARIS \\ Desafía la lógica}

\section{Text 4}

FELICIA - LA NUEVA CARA

GRANDE, RESISTENTE Y ECONÓMICO

Así es el nuevo Skoda Felicia, el mayor coche de su categoría. Un coche hecho para durar, con la resistencia de un Skoda, fiable y seguro, con la garantía del grupo Volkswagen, y una excelente relación producto-precio. Pruébelo, se sorprenderá.

Text 3 is accompanied by a picture of a small girl blowing bubbles, with further questions such as ipuede lo pequeño ser espacioso?, which, together with the text, and, specifically, the recurrent play with the idea of logic, evoke intertextually the world of Alice in Wonderland (at least in my own reading of the text), a world where sizes and properties are not permanent and can change at will. The choice of the pronoun $t u$, as in $i$ No crees...?, together with the colours of the picture (bright and striking orange) and the challenge Desafia la lógica seem to indicate that the advertisement is directed at a rather young audience. The properties of the car are introduced as presupposed information by means of negative interrogative clauses which seek the addressee's agreement. As was explained in section 2, this advertisement illustrates the conversational tone of many advertisements, where the receiver is addressed directly and is involved in a dialogic discourse structure. Significantly, most of the properties of the car are presented as pairs of apparently incompatible terms (not logical), which, however, are presented as possible in the car advertised (logical): ligero y resistente, bello y práctico.

In text 4 the pronoun chosen is usted (Pruébelo, se sorprendera), and the properties of the car form part of frames which have to do with giving a sense of security (grande, resistente, fiable, seguro) which contrast with the challenging nature of the advertisement in text 3. Similarly, a point is made of the economical price, something which is not mentioned in text 3 and a list of the objective properties of the car is also provided. The features of text 4 seem to indicate that the target audience is older than that of text three, and 
thus presupposes that this audience will value more highly properties that reflect security and reliability, which can be described objectively, while text three presupposes that a younger audience will value more highly properties which enable one to break rules and which have a more subjective appeal.

To end, intertextuality is crucial in the processing of many ads, as is illustrated by the advertisement which follows. It may be argued that intertextuality is a kind of frame knowledge evocation which brings into the discourse the knowledge of other relevant texts. The ad which follows bases its appeal on the intertextual play with advertisements of toys for children, while it is in fact an advertisement of the association for the defence of children's rights Manos Unidas:

\section{Text 5 \\ I (love) Sushila \\ Sushila siempre dice sí \\ Sin documentación \\ ¿Quieres jugar con ella? \\ Varios modelos}

A partir de 10 años

Explotación sexual, niños en la guerra, trabajo infantil...250 millones de personas son utilizadas como objetos. Todas tienen nombre: esclavos.

ARRIÉSGATE. OYE SU VOZ

\section{Manos Unidas}

The first part of the text is inserted in the picture of what seems to be a box with a doll, the doll-girl Sushila. This is the part of the ad which reproduces intertextually the features of a toy advertisement. Pronouns are used to create multiple meanings; thus, the use of the first person pronoun $I$ invites an identification with the receiver, placing him directly in the situation depicted as a direct participant. Then the receiver is addressed as you, in $i$ Quieres jugar con ella? Where a conversational tone is introduced between sender and receiver. This (shocking) invitation is substituted by the final invitation or plea of the advertisement, ARRIESGATE. OYE SU VOZ, which appeals to the receiver's feeling of solidarity with the exploited children.

\section{Conclusion}

A text world model of discourse has been proposed for the analysis and discussion of some of the textual and discursive features of advertisements. The following concluding remarks may be drawn: first, deictic terms play a crucial role in the establishment of a relation between sender and addressee and in setting the situation which starts the world-building process; second, knowledge frames, which are evoked once the deictic parameters are established, contribute to the fleshing out of the worlds depicted in advertisements by 
evoking conceptual domains which are structured according to the receiver's experience and cultural background. Both deixis and frame knowledge, together with other linguistictextual devices are exploited in advertising discourse in order to create vivid situations which appeal directly to the addressee's attention and interests.

\section{Notes}

1. For a semiotic interpretation of advertising discourse see Kress and van Leuwen (1996) Reading Images: The Grammar of Visual Design.

2. For a detailed discussion of the features of context with regard to register variation see, for example, Eggins (1994).

3. For a discussion of world view and ideology, see Fowler (1986: 17).

4. An influential definition of text has been that proposed by de Beaugrande and Dressler (1981: 3) where "a TEXT is a communicative occurrence which meets seven standards of textuality." These seven standards are cohesion, coherence, intentionality, acceptability, informativity, situationality, intertextuality.

5. For a discussion of the functions of deictics such as here and today in advertising discourse see Campos Pardillos (1995).

\section{Works cited}

de Beaugrande, R. and W. Dressler (1981): Introduction to Text Linguistics. London: Longman. Brown, R. and A. Gilman (1964): "The pronouns of power of solidarity." In T. Sebeok ,ed., Style in Language, Cambridge, Mass.: MIT Press, 53-276.

Campos Pardillos, M.A. (1995): "Deixis as a reference to an alleged shared situation in persuasive discourse." Revista Alicantina de Estudios Ingleses 8: 57-67.

Carter R.A. W. Nash (1990): Seeing Through Words. Oxford: Blackwell.

Carter, R.A. et al. (1997): Working with Texts. London: Routledge and Kegan Paul. Cook, G. (1992): The Discourse of Advertising. London: Routledge and Kegan Paul. (1994): Discourse and Literature. London: Routledge and Kegan Paul.

van Dijk, T.A. (1977): Text and Context: Explorations in the Semantics and Pragmatics of Discourse. London: Longman.

van Dijk, T.A. and W. Kintsch (1983): Strategies of Discourse Comprehension. New York: Academic Press.

Eggins, S. (1994): An Introduction to Systemic Functional Linguistics. London: Pinter Publishers.

Fauconnier, G. (1985): Mental Spaces. Cambridge: Cambridge University Press.

Fillmore, C. (1985): "Frames and the semantics of understanding." Quaderni di Semantica VI(2): 222-53.

Fowler, R. (1986): Linguistic Criticism. Oxford: Oxford University Press.

Goddard, A. (1998): The Language of Advertising. London: Routledge and Kegan Paul.

Goodwin C. and A. Duranti (1992): "Rethinking context: an introduction." In: A. Duranti and C. Goodwin, eds., Rethinking Context. Cambridge: Cambridge University Press, 1-12. 
Green, K. (ed.)(1995): New Essays in Deixis. Amsterdam: Rodopi.

(1995): "A revaluation of concepts and categories." In K. Green, ed., New Essays in Deixis, 11-27.

Halliday, M.A.K. (1973): Explorations in the Functions of Language. London: Arnold.

- (1994): An Introduction to Functional Grammar (2nd edition). London: Arnold.

Lakoff, G. (1987): Women, Fire and Dangerous Things. Chicago: University of Chicago Press.

Lakoff, G. and M. Johnson (1980): Metaphors We Live By. Chicago: The University of Chicago Press.

Levinson, S. (1983): Pragmatics. Cambridge: Cambridge University Press.

Lyons, J. (1995): Linguistic Semantics. Cambridge: Cambridge University Press.

Schank, R.C. (1982): Dynamic Memory. Cambridge: Cambridge University Press.

Semino, E. (1997): Language and World Creation in Poetry and Other Texts. London: Longman.

Verdonk, P. and J.J. Weber (eds.)(1995): Twentieth Century Fiction: From Text to Context. London: Routledge and Kegan Paul.

Werth, P. (1995a): "How to build a world (in a lot less than six days and using only what's in your head)." In K. Green, ed., New Essays in Deixis. Amsterdam: Rodopi, 49-81.

- (1995b): "World enough, and time': Deictic space and the interpretation of prose." In P. Verdonk and J.J. Weber, eds., Twentieth Century Fiction: From Text to Context. London: Routledge and Kegan Paul, 181-206.

(1999): Text Worlds: Representing Conceptual Space in Discourse. London: Longman. 